\title{
Investigating the Influence of Ethical Climate on Trust in Organization and Trust in Supervisor in Albaha Province, Saudi Arabia, Using Victor and Cullen's Framework
}

\author{
Faris Alghamdi \\ Business School, Albaha Univeristy, Albaha, KSA \\ Email: farissg@hotmail.com
}

How to cite this paper: Alghamdi, F. (2018) Investigating the Influence of Ethical Climate on Trust in Organization and Trust in Supervisor in Albaha Province, Saudi Arabia, Using Victor and Cullen's Framework. Journal of Service Science and Management, 11, 383-398.

https://doi.org/10.4236/jssm.2018.114027

Received: July 4, 2018

Accepted: August 6, 2018

Published: August 9, 2018

Copyright $\odot 2018$ by author and Scientific Research Publishing Inc. This work is licensed under the Creative Commons Attribution International License (CC BY 4.0).

http://creativecommons.org/licenses/by/4.0/

\begin{abstract}
Organizations' ability to develop trusting relationships is an increasingly significant source of competitive advantage. The current study explores which ethical climate types facilitate and foster higher levels of trust, i.e. trust in one's supervisor and trust in organization in some public organizations in Albaha province, applying the Victor and Cullen's (1988) framework of ethical climate. Initial findings of this study showed that most of the participants perceived the presence of caring, laws, and rules climate. Hierarchical multiple regression analyses revealed that laws climate was positively and significantly related to trust in organization, as well as laws and caring climate were positively and significantly related to trust in supervisor. No support was found for any effects of ethical climate types, i.e., instrumentality and independence on trust in organization and trust in supervisor.
\end{abstract}

\section{Keywords}

Ethical Climate, Trust in Organization, Trust in Supervisor

\section{Introduction}

Research has demonstrated that elevated levels of trust will maximize benefits at multiple levels of analysis, e.g. an organizational level [1]. Scholars of ethical climate showed that the climate of an organization influences the behavior of employees in a given setting. It stressed that employees can accurately judge their setting's ethical climate and rate it on a survey [2]. The practices of successful managers within an organization can impact ethical behavior. For exam- 
ple, if managers believe that unethical behavior is needed for success, such a perception is more likely to be a strong motivation for unethical behavior [3]. Organizational trust is increasingly identified as a crucial coordinating mechanism among colleagues, units, and functions within an organization, as well as a significant prerequisite for organizational success [4] [5].

Employees who desire to succeed are frequently the foundation for unethical behavior in a workplace setting. For instance, Lehman Brothers, AIG, WorldCom, and others are organizations where employees acted in unethical ways to achieve success and raise wreath [6]. When Equity Funding Corporation collapsed financially in 1973, the ensuring investigation revealed that dozens of employees assisted in perpetuating or concealing the fraud, and most were influenced by monetary rewards [7]. One of the rules in social exchange theory is the norm of reciprocity. It proposes that there is a social norm explaining that when person $A$ assists person $B$, hence person $B$ is required to assist person $A$ or at least not hurt person A [8] [9] [10] [11]. Research in organizational trust claimed that in expectations of reciprocity, employees engage in trust behavior because they anticipate others to do the same [12]. According to [13], employees will increase trust when their supervisors are perceived as being ethical. Additionally, employees learn proper behavior through actions taken by their supervisors [14]. High trust levels in an organization demonstrated positive outcomes, including diminishing operating costs [15], maintaining workplace security [16], enhancing economic performance [17], and increasing employee productivity [18]. Moreover, empirical studies revealed that organizational ethical climate associated with organizational commitment [19] and job satisfaction [20].

In November 2017, Saudi Arabia government announced that 200 people including some of the royal family, current and former ministries, top officials, and others were detained in anti-corruption crackdown. Saudi attorney general said in a statement that Saudi authorities believed that at least $\$ 100$ billion had been misused through systematic corruption and embezzlement over several decades [21]. Besides, so far, it is confirmed that only two studies examined the association between ethical climate and organizational trust, i.e. trust in one's supervisor and trust in the overall organization, and both were carried out in a western context ([6] [22]).

Therefore, it becomes vital to investigate how ethical climate can affect trust in supervisor and in organizations in the Saudi context. This study explores which ethical climate types facilitate and foster higher levels of trust, i.e. trust in one's supervisor and trust in organization in some public organizations in Albaha province, applying the Victor and Cullen's framework of ethical climate. The next section will cover literature review, followed by methodology, data analysis, results, discussion, limitation and conclusion.

\section{Literature Review}

\subsection{Ethical Climate}

Ethics generally defines as just or rights norms of behavior among people in a 
given circumstance. These norms refer to accepted social values involving justice and fairness. Ethics entails essential human relationships between parties in an exchange process, i.e. organizational members (supervisors, coworkers, and subordinates), rivals, customers, and the general public. Each one of these players in the exchange process is bound by duties and responsibilities [23]. Ethical climate refers to a set of norms in an organization dictating how employees in that organization decide what is ethical and what is unethical. It concentrates on the process of making ethical decisions instead of the ethical decision per se [6].

Victor and Cullen [24] [25] coined the organizational ethical climates and defined ethical work climate-a type of work climate-as "the prevailing perceptions of typical organizational practices and procedures that have ethical content constitute the ethical work climate" (p. 101). They have examined different types of ethical climates in organizations applying moral development [26] and socio-cultural theories of organization [27] [28] [29]. Their ethical climate theory (ECT) framework consisted of a two-dimensional model of ethical climate types, namely ethical philosophy or ethical theory and sociological theory of reference groups or locus of analysis.

The first dimension, the ethical criteria, is the reasoning process whereby ethical decisions are made. It is categorized as egoism (maximizing self-interest), benevolence (maximizing collective interests; utilitarianism), and principle (adherence to principle; deontology), which are associated with Kohlberg's (1984) three levels of moral reasoning, i.e. pre-conventional, conventional, and post-conventional. The criteria for benevolence construct concerns with decisions and actions taken to achieve the greatest good for the greatest number of people. On the other hand, the criteria for principle construct concerns with laws, rules, and procedures, hence followed to indicate decisions and actions. The second dimension links with the scope of ethical issues being deliberated and constitutes the locus of analysis utilized as a referent in ethical decisions, or the focus.

Following the sociological theory of roles and referent group in organizations [27] [28], Victor and Cullen [24] [25] differentiate among individual-level, group-level, and societal-level. These are termed individual, local, i.e. organization per se, and cosmopolitan, i.e. external to the organization. Crossing the three levels on each dimension generates nine theoretical climate types, as illustrated in Figure 1, self-interest, company profit, efficiency, friendship, team interest, social responsibility, personal morality, company rules and procedures, and laws and professional codes [1] [30] [31].

Nevertheless, Victor and Cullen [32] identified six types of ethical climates, namely professionalism or laws (employees are expected to comply with the laws and professional standards), caring (a major consideration is what is best for everyone in an organization), rules (everyone is expected to stick by an organization's rules and procedures), instrumental (in a given organization, employees protect their own interest above all else), efficiency (the most efficient way is the right way in a given organization), and eventually independence (each employee 


\section{Locus of Analysis}

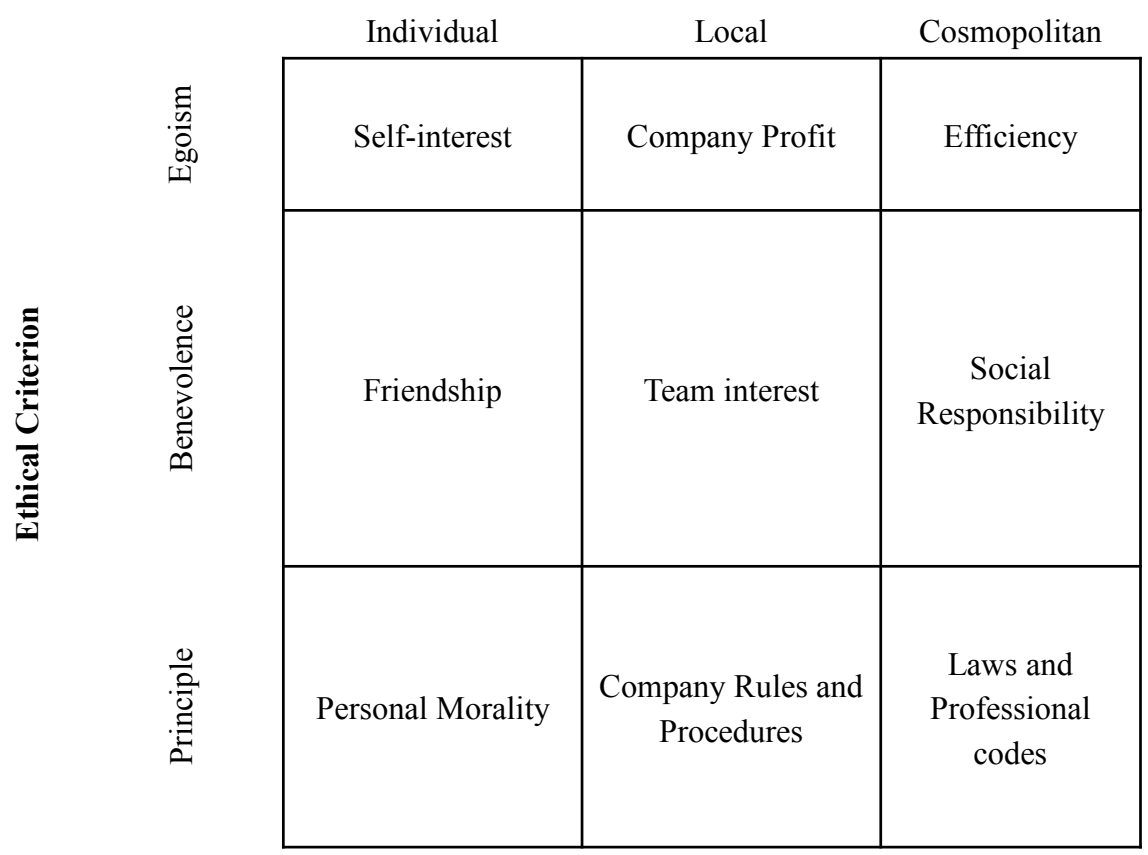

Figure 1. Theoretical climates types [3].

in a given organization decides for themselves what is right and wrong). Having explained that, five ethical climate types will be applied for the purpose of the present study [33].

\subsection{Trust}

People who work together usually involve interdependence, hence depend on each other in different ways to achieve their own and organizational goals. A number of attempts have been made by theorists to explain mechanisms so that risk related to working together can be reduced. Their main goal was to design theories to regulate, enforce, and/or encourage compliance to prevent potential results of broken trust [34]. Trust is a central element of the successful working relationship between organizational members at different organizational levels. It helps facilitate cooperation, manage differences, promote information sharing, and boost openness and mutual acceptance. Given that, [35] defined trust as "a psychological state comprising the positive expectation that another party will perform particular actions that are important to oneself, coupled with a willingness to accept vulnerability which may arise from the actions of the other party"(p. 105).

From this definition, a party (trustor) holds willingness to be vulnerable to the actions of another party (trustee), regardless of its ability to monitor or control. The focus is on the trustor's willingness to trust, or trustfulness, instead of trustee's trustworthiness [36]. There may be some confusion between trust and trustworthiness; however, the former refers to the perceived qualities and intentions of the trustee, while the latter refers to the trustee's actual qualities and in- 
tentions [37]. Trust dimensions based on sources of trust stemmed from the trustor's side are: calculus-based trust (a trust based on deterrence or the balance of results perceived by the trustor and trustee), knowledge-based trust (how well the trustor can realize and forecast the trustee's actions), and identity-based trust (considered to be a result of mutual understanding). Conversely, the trust dimensions based on predicting the trustee's characteristics are: competence or ability trust (the competence of the trustee to attain what is expected from him or her), benevolence is "the extent to which a trustee is believed to want to do good to the trustor, aside from egocentric profit motive" [32], and integrity (perception of trustor that trustee adheres to a set of principles that are acceptable to the trustor) [22] [38].

\subsection{Trust in Supervisor}

Trust has been a crucial area of interest of scholars for many years and has been linked to a spectrum of job antecedents and outcomes. It is seen as a dyadic construct wherein the behavior of a party impacts the perceptions and actions of another party [39]. Having said that, trust has recognized as a significant aspect of numerous leadership theories, e.g. associating with leader-member exchange theory, transformational leadership theory, charismatic leadership theory, paternalistic leadership theory, and ethical leadership theory [13] [31]. According to [40], trust is generated from social exchanges processes such that followers feel obligated to reciprocate fair treatment by the supervisor utilizing behavior that benefits a given organization.

[41] claimed that organizational trust includes two components, that is, trust in one's supervisor and trust in the overall organization. Thinking on how trust evolves within an organization has reviewed, and therefore concluded that trust is seen as evolving from social relationships, indexed through frequency and length of contact, i.e. communication among organizational members (followers and supervisors). These relationships are supposed to build reputation and confidence in the trusting parties. On the other hand, trust is recognized as evolving from organizational forms and management philosophies, i.e. organizational ethical climate [42]. As [43] argued that for a supervisor to be trusted, they should walk the talk and talk the walk. Eventually, [44] observed that "the more trust and loyalty expressed by subordinates towards their supervisor the more positively the supervisor was perceived to behave" (p. 305).

\subsection{Trust in Organization}

[45] defined organizational trust as employees' belief that others, i.e. individual or team will make a good faith effort to maintain commitment, honest, and not take advantage of another. Trust exists at different levels of an organization, an interpersonal level (e.g., between individual and co-worker, supervisor, and subordinate), a group level (e.g., between teams, and departments), an organizational level (e.g., between individuals, groups and an organization), and an 
inter-organizational level, i.e. between organizations [30]. Organizational trust entails the willingness to be vulnerable and takes a risk regarding the probability that another party will not fulfill the expectations of this benevolent behavior [46].

Trust in an organization has been illustrated as a multidimensional variable that can be lateral or vertical. The former refers to the trust that can be seen between coworkers or equals sharing a similar employment position. The latter, however, refers to trust between employees and their supervisors, their subordinates, top management, or an organization as a whole [47] [48]. Some scholars claimed that trust in ongoing relationships between individuals and organizations are very important because, without trust, the transaction costs of maintaining that relationship augments extremely for both parties [6]. Internal trust refers to the climate of trust within an organization. Those organizations that have high levels of internal trust will be more successful, adaptive, and innovative than others that have low levels of trust [37] [49].

\section{Hypothesis Development}

The influence of ethical climate on trust in supervisor and organization has been investigated, mainly in Weston cultures. Trust of the employees on their supervisors is essential for effective functioning of an organization. A recent empirical study [50] was carried out in India, and data were collected from a sample of 270 employees in 10 organizations to examine the association between ethical climate types and trust in management. The results indicated that ethical climate types, i.e. caring, laws and codes, and rules and procedures were significant predicates of trust in management. Nevertheless, the impact of ethical climate, i.e. instrumentality, and independence on trust in management was not supported. Another empirical study was undertaken in Poland [1], and data were collected from a sample of 178 managerial employees at seven hospitals. The main goal of study was to examine the relationship between ethical climates, i.e. egoistic, benevolent, and principle and trust in supervisor and trust in organization. The findings showed that egoistic climates were negatively related to trust in supervisor and trust in organization. Conversely, benevolent climates were positively related to trust in supervisor and trust in organization. However, no support was attained for any sort of relationship between principled climates and either of two trust elements.

[4] claimed that all three factors of ability, benevolence, and integrity can contribute to a group or an organization, hence provided an example of a supplier-buyer relationship. [13] conducted an empirical study using a sample of 393 salespeople to examine the effects of ethical climate on organizational identification, supervisory trust, and turnover among salespeople. Particularly, the result revealed that aspects of ethical work climate were related directly to trust in supervisor. Another empirical study [51] was conducted in the United States on a sample of 344 salespeople working for a global pharmaceuticals company. It 
aimed at examining the integrated effects of ethical climate and supervisory trust on salesperson's job attitudes and intentions to quit. Precisely, the finding showed that ethical climate is a significant predictor of trust in supervisor. Finally, an empirical study [6] was carried out at a university in the Southern United States on a sample of 374 alumni association. The objective of the study was to examine the relationship between ethical and organizational trust and to test whether increased business performance changes this relationship. The results indicated a positive relationship between three aspects of ethical climate, i.e. caring, laws, and rules and organizational trust, as well as a negative relationship between one ethical climate aspect, i.e. instrumental. From the discussion above, the following hypotheses are formulated, see Figure 2.

$\mathrm{H1}$ : As ethical climate for caring, laws, and rules increases, trust in organization increases.

H2: As ethical climate for instrumentality and independence increases, trust in organization decreases.

H3: As ethical climate for caring, laws, and rules increases, trust in supervisor increases.

H4: As ethical climate for instrumentality and independence increases, trust in supervisor decreases.

\section{Method}

\subsection{Participants and Procedure}

Data were collected from a sample of male employees working in public organizations in Albaha province. The questionnaire was distributed in paper form accompanying by a cover letter illuminating the goal of the study and an assurance of confidentiality and anonymity. In the letter, there were instructions for completing and handing back the questionnaire to the principal researcher within two weeks. Excepting demographic variables, the questionnaire was translated from the English language to the Arabic language, which is the official language for all potential subjects, using a back-translation technique [52]. Therefore, a professor at Albaha University translated the original questionnaire into Arabic language and then another professor at the same university translated back to the English language without references to the original English version. Both professors are fully bilingual and are working in the business

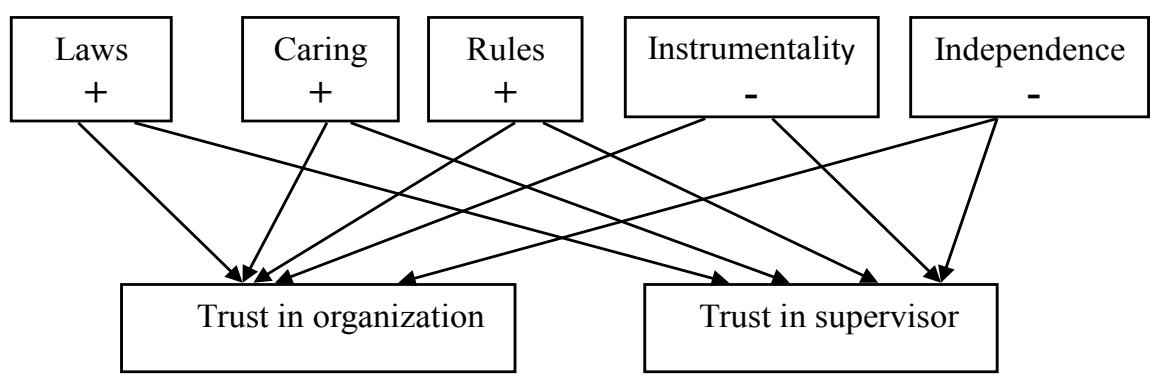

Figure 2. Conceptual model and hypotheses. 
department. After that, the researcher went carefully over both versions and made revisions necessary for ensuring a complete and accurate meaning of the original text of the questionnaire, which, in turn, enhancing ease of use, readability, and an appropriate level of formality.

The current study used a self-report questionnaire administered to 198 male employees working on a full-time basis. Of the distributed questionnaires, 121 responses were received and useful for analysis, giving a response rate of $61 \%$. All participants were male, and the majority of them (46.3\%) were in the range of 29 to 39 years old, and most of the respondents (46.3\%) received a bachelor's degree. Most of the respondents (30.6\%) had work experience in the rage of 5 to 10 years; lastly, the mainstreams of participants were working at middle-level management (57.9\%). Table 1 shows the demographic composition of the respondents.

\subsection{Measures}

The present study applied a descriptive cross-sectional design. The questionnaire used in this study is structured, self-administered, and consists of four parts. The first part includes demographic characteristics of participants: age, educational level, work experience, and management level. Participants reported their age in years, educational level $(1=$ less than high school, $2=$ high school, $3=$ undergraduate, $4=$ graduate), work experience $(1=$ less than 5 years, $2=5-10$ years, $3=11$ - 16 years, $4=$ more than 17 years $)$, and management level $(1=$ top management, 2 = middle management, 3 = first-line management).

The second part represents organizational ethical climate that was measured utilizing six global measures coined by [3] [51] based on the seminal work of Victor and Cullen $(1987,1988)$, and the ECQ instrument given in [52] Respondents were asked to rate these items on a 5-point Likert type scale, ranging from 1 (strongly disagree) to 5 (strongly agree). Cronbach's alphas for this scale in the present study were 0.50

The third part is trust in supervisor that was measured using 7-items developed by [53]. Participants were asked to rate these items on a 5-point Likert type scale, ranging from 1 (strongly disagree) to 5 (strongly agree). Cronbach's alphas for this scale in the present study were .66. The last part includes trust in organization. It is measured with the scaled coined by [40]. Participants were asked to rate these items on a 5-point Likert type scale, ranging from 1 (strongly disagree) to 5 (strongly agree). Cronbach's alphas for this scale in the present study were .84 .

\section{Data Analysis}

Preliminary analyses of the data were a descriptive statistic (means, standard deviations) along with correlations of study variables, as shown in Table 2.

Next, separate two-step hierarchical multiple regression analyses for each dependent variables, i.e. trust in management and trust in supervisor were 
Table 1. Demographic variables of the respondents $(N=121)$.

\begin{tabular}{|c|c|c|c|}
\hline Variable & Category & Number of respondents & Percentage \\
\hline \multirow[t]{4}{*}{ Age } & $18-28$ & 13 & 10.7 \\
\hline & $29-39$ & 56 & 46.3 \\
\hline & $40-50$ & 43 & 35.5 \\
\hline & $>50$ & 9 & 7.4 \\
\hline \multirow[t]{4}{*}{ Education } & Less than high school & 5 & 4.1 \\
\hline & High school & 39 & 32.2 \\
\hline & Undergraduate & 56 & 46.3 \\
\hline & Graduate & 21 & 17.4 \\
\hline \multirow[t]{4}{*}{ Work experience } & $<5$ years & 20 & 16.5 \\
\hline & $5-10$ & 37 & 30.6 \\
\hline & $11-16$ & 33 & 27.3 \\
\hline & $>17$ & 31 & 25.6 \\
\hline \multirow[t]{3}{*}{ Management level } & Top management & 14 & 11.6 \\
\hline & Middle management & 70 & 57.9 \\
\hline & First-line management & 37 & 30.6 \\
\hline
\end{tabular}

Table 2. Means, standard deviations, and correlations among main variables $(N=121)$.

\begin{tabular}{ccccccccc}
\hline & Mean & SD & 1 & 2 & 3 & 4 & 5 & 6 \\
\hline Law & 4.1 & 0.99 & & & & & & \\
Car & 4.1 & 0.92 & $0.41^{* *}$ & & & & & \\
Rul & 4.1 & 0.90 & $0.70^{* *}$ & $0.37^{* *}$ & & & & \\
Ins & 3.5 & 1.3 & $-0.23^{* *}$ & 0.02 & $-0.20^{*}$ & & & \\
Ind & 3.3 & 1.2 & 0.04 & 0.10 & -0.1 & $0.36^{* *}$ & & \\
TrO & 3.4 & 0.98 & $0.51^{* *}$ & 0.16 & $0.40^{* *}$ & $-0.19^{*}$ & 0.12 & \\
TrS & 3.5 & 0.64 & $0.39^{* *}$ & $0.38^{* *}$ & $0.33^{* *}$ & 0.11 & $0.20^{*}$ & $0.47^{* *}$ \\
\hline
\end{tabular}

Note Law $=$ Laws; $\mathrm{Car}=$ caring; $\mathrm{Rul}=$ rules; $\mathrm{Ins}=$ instrumentality; $\mathrm{Ind}=$ independence; $\mathrm{TrO}=$ trust in organization; $\operatorname{Tr} S=$ trust in supervisor. ${ }^{*} P<05 ;{ }^{*} P<01,1$-tailed significance.

undertaken to examine study hypotheses. Based on [54], variables of lower order were introduced first, and the higher order terms later. Therefore, control variables were entered in first step (gender, age, educational level, work experience, and management level) followed by predictor variables (laws, caring, rules, instrumentality, and independence).

\section{Result}

Table 2 shows the means, standard deviation, correlations for the key variables in the study. An ethical climate governed by caring $(\mathrm{M}=4.14, \mathrm{SD}=0.99)$, laws $(\mathrm{M}=4.13, \mathrm{SD}=0.92)$, and rules $(\mathrm{M}=4.12, \mathrm{SD}=0.90)$ was the strongest, fol- 
lowed by instrumentality $(\mathrm{M}=3.5, \mathrm{SD}=1.3)$. The participants perceived, to a lesser extent, that their organization's ethical climate stressed on independence $(\mathrm{M}=3.3, \mathrm{SD}=1.2)$.

Interrelations exist among the five ethical climate types and with the dependent variables of trust in organization and trust in supervisor. Laws' climate is positively and significantly associated with caring $(r=-0.41, P<.01)$, rules $(r=$ $0.70, P<0.01)$, trust in organization $(r=0.51, P<0.01)$, trust in supervisor $(r=$ $0.39, P<0.01)$, and negatively and significantly with instrumentality $(r=-0.23$, $P<0.01)$. This result is consistent with the results obtained by [30]. Caring climate is positively and significantly associated with rules $(r=0.37, P<0.01)$ and trust in supervisor $(r=0.38, P<0.01)$. Trust in organization is positively and significantly associated with rules $(r=0.40, P<0.01)$ and negatively and significantly with instrumentality $(r=-0.19, P<0.05)$. Finally, trust in supervisor is positively and significantly associated with rules $(r=0.33, P<0.01)$, independence $(r=0.20, P<0.05)$, and trust in organization $(r=0.47, P<0.01)$.

It would be premature to draw conclusions from the above results regarding testing study hypotheses because the predictors, i.e. ethical climates types are interrelated. Thus, two separate hierarchical multiple regression analyses were performed to test the study hypotheses, each of which was for each dependent variable. The first hypothesis states that as the ethical climate for caring, laws, and rules increases, trust in organization increases. Hierarchical multiple regression analysis's (Table 3 , model $2 \mathrm{~A}$ ) results showed only support for laws $(\beta=$ $0.47, P<0.01)$, and not for caring $(\beta=-0.05, P>0.05)$, and rules $(\beta=0.10, P>$ 0.05). Hence, $\mathrm{H} 1$ was partially supported. The second hypothesis states that as the ethical climate for instrumentality and independence increases, trust in organization decreases. Hierarchical multiple regression analysis's (Table 3, model $2 \mathrm{~A})$ results showed no support for instrumentality $(\beta=-0.12, P>0.05)$ and independence $(\beta=0.11, P>0.05)$. Therefore, $\mathrm{H} 2$ was not supported.

The third hypothesis states that as the ethical climate for caring, laws, and rules increases, trust in supervisor increases. Hierarchical multiple regression analysis's (Table 3, model $2 \mathrm{~B}$ ) results showed only support for laws $(\beta=0.29, P$ $<0.05)$ and caring $(\beta=0.22, P<0.05)$ and not for rules $(\beta=0.09, P>0.05)$. Hence, H3 was partially supported. The last hypothesis states that as the ethical climate for instrumentality and independence increases, trust in supervisor decreases. Hierarchical multiple regression analysis's (Table 3 , model $2 \mathrm{~B}$ ) results showed no support for instrumentality $(\beta=0.15, P>0.05)$ and independence $(\beta$ $=0.07, P>0.05)$. Therefore, H4 was not supported.

\section{Discussion}

The main objective of this study is to explore which ethical climate types facilitate and foster higher levels of trust, i.e. trust in one's supervisor and trust in organization in some public organizations in Albaha province, applying the Victor and Cullen's (1988) framework of ethical climate. As for trust in supervisor, the 
Table 3. Hierarchical regression analysis in predicting dependent variables $(N=121)$.

\begin{tabular}{ccccc}
\hline & \multicolumn{2}{c}{ Trust in organization } & \multicolumn{2}{c}{ Trust in supervisor } \\
\hline & Model 1A & Model 2A & Model 1B & Model 2B \\
\hline Control variables & & & & \\
\hline Age & -0.01 & -0.08 & -0.03 & -0.09 \\
EduL & -0.07 & -0.07 & -0.05 & -0.08 \\
WorE & $-0.28^{*}$ & $-0.27^{*}$ & -0.20 & -0.20 \\
ManL & -0.02 & -0.07 & -0.06 & 0.00 \\
\hline Predictor variables & & & & $0.29^{*}$ \\
\hline Law & & $0.47^{* *}$ & & $0.22^{*}$ \\
Car & & -0.05 & & 0.09 \\
Rul & & 0.10 & & 0.15 \\
Ins & & -0.12 & & 0.07 \\
Ind & & 0.11 & & 0.258 \\
$\Delta \mathrm{R}^{2}$ & 0.085 & 0.300 & 0.081 & 0.338 \\
$\mathrm{R}^{2}$ & 0.085 & 0.385 & 0.081 & $8.64^{* *}$ \\
$\Delta \mathrm{F}$ & $2.68^{*}$ & $10.81^{* *}$ & $2.55^{*}$ & \\
\hline & & & & \\
\hline
\end{tabular}

Note: Age = age in years; EduL = educational level; WorE = work experience; $\mathrm{ManL}=$ management level; Law = Laws; Car = caring; Rul = rules; Ins = instrumentality; Ind = independence; $\mathrm{TrO}=$ trust in organization; $\mathrm{TrS}=$ trust in supervisor. The results of variance inflation factor (VIF) did not show any problems of multicollinearity. Predictor variables were centered. ${ }^{\star} P<0.5 ;{ }^{* *} P<0.1$.

study found support for two types of ethical climate, laws and caring. Moreover, the study provided support for one type of ethical climate, i.e., laws in association with trust in organization. These findings are consistent with previous studies [1] [6] [30] [42].

The findings of the current study indicated that negative climate types (instrumentality and independence) had an insignificant effect on either of the two trust components, namely trust in organization and trust in supervisor. These findings are in line with the previous study undertaken in Indian context [30], hence not as expected. Along with that, findings of this study showed that most of the participants perceived the presence of caring, laws, and rules climate. These findings are similar to those found in previous research in which workplace can have the presence of multiple ethical climate types [2] [33] [51] [55].

\section{Limitations}

Some limitations can be found in the present study, deriving from them suggestions for future avenues of research. The first limitation is that the current study excluded women from participating in this study. This happened because the majority of public organizations included in this had few female employees or had not. Hence, researchers may include female participants in the future 
study to understand these variables and their effects from women perspectives. Another limitation centered in using cross-sectional method, which captures information based on data collected at one signal point in time. Therefore, longitudinal study is favored so that data can be collected over a long period of time. Finally, this study applied self-report questionnaire, hence subject to social desirability bias and common method variance. Future research can applied other methods to collect data such as an interview.

\section{Conclusions}

Ethical climate types as an antecedent of trust in organization and trust in supervisor have been examined in the context of a developing country, Saudi Arabia. This study found that ethical climate based on laws, i.e. employees, is expected to comply with the law and processional slandered impacted positively on trust in organization and trust in supervisor. Employees in such environment are principle-oriented in which opportunistic behavior is likely to reduce and violations of laws are likely to be penalized. It is recommended that public organizations, in order to facilitate and foster a high level of trust, can improve rules climate in which everyone is expected to stick by an organization's rules and procedures. This can be done through training programs, incentive programs, and a reward-punishment system.

Caring climate, i.e. maximizing joint interest had effects on trust in supervisor and not on trust in organization. That is, employees feel that their organizations do not care about them as their supervisors do. It can be explained by the fact that public organizations focus more on delivering public services to people using budget provided via governments. Employees in public organizations believed that their interests can be minimized because policies in public sector do not give them more benefits than private scoter. Hence, they would be inclined to show more trust in supervisors than trust in organizations. Another explanation is culture. Some scholars argued that trust had its basis in employees rather than the organizations themselves, and this shaped by society's culture. This is true because Saudis culture is collective, and therefore trust, in general, is based on the collective trust of organizational members. It is recommended that public organizations can have more trust from employees through changing their policies considering employees' interests rather than only organizations' interests. This argument is in line with the norm of reciprocity as explained by social exchange theory.

The negative ethical climate types, i.e. instrumentality and independence had no effects on trust in organizations and trust in supervisors. This may be explained by some societal dimensions such as hypocrisy, power distance, nepotism, and favoritism. It is recommended that public organizations focus on eliminating such negative behaviors by establishing new policies and building new positive culture. Moreover, since ethical climate is a reflection of management attitude and philosophies, true morality, i.e. the fairness of the ongoing decision 
process and right treatment of employees for virtuous reasons are more likely to result in trust.

\section{Acknowledgements}

This research is a part of a project entitled "Investigating the influence of ethical climate on trust in organization and trust in supervisor in Albaha province, Saudi Arabia, using Victor and Cullen's framework" (Grant No. 0-1939). The assistance of the Deanship is gratefully acknowledged.

\section{Conflicts of Interest}

The authors declare no conflicts of interest regarding the publication of this paper.

\section{References}

[1] Simha, A. and Stachowicz-Stanusch, A. (2015) The Effects of Ethical Climates on Trust in Supervisor and Trust in Organization in a Polish Context. Management Decision, 53, 24-39. https://doi.org/10.1108/MD-08-2013-0409

[2] Deshpande, S.P., Joseph, J. and Shu, X. (2011) Ethical Climate and Managerial Success in China. Journal of Business Ethics, 99, 527-534.

[3] Deshpande, S.P. (1996) The Impact of Ethical Climate Types on Facets of Job Satisfaction: An Empirical Investigation. Journal of Business Ethics, 15, 655-660. https://doi.org/10.1007/BF00411800

[4] Schoorman, F.D., Mayer, R.C. and Davis, J.H. (2007) An Integrative Model of Organizational Trust: Past, Present, and Future. Academy of Management Review, 32, 344-354. https://doi.org/10.5465/amr.2007.24348410

[5] Audi, R. (2008) Intuition, Inference, and Rational Disagreement in Ethics. Ethical Theory and Moral Practice, 11, 475-492. https://doi.org/10.1007/s10677-008-9123-9

[6] Lilly, J., Duffy, J.A. and WIpawayangkool, K. (2016) The Impact of Ethical Climate on Organizational Trust and the Role of Business Performance: If Business Performance Increases, Does Ethical Climate Still Matter? Journal of Behavioral and Applied Management, 17, 33.

[7] Woolf, E. and Hindson, M. (2011) Audit and Accountancy Pitfalls: A Casebook for Practising Accountants, Lawyers and Insurers. John Wiley \& Sons, Hoboken.

[8] Gouldner, A.W. (1960) The Norm of Reciprocity: A Preliminary Statement. American Sociological Review, 25, 161-178. https://doi.org/10.2307/2092623

[9] Meeker, B.F. (1971) Decisions and Exchange. American Sociological Review, 36, 485-495. https://doi.org/10.2307/2093088

[10] Blau, P.M. (1964) Exchange and Power in Social Life. John Wiley \& Sons, NY.

[11] Homans, G.C. (1961) Social Behavior: Its Elementary Forms. Harcourt, Brace, and World, New York.

[12] Korsgaard, M.A., Brower, H.H. and Lester, S.W. (2015) It Isn't Always Mutual: A Critical Review of Dyadic Trust. Journal of Management, 41, 47-70. https://doi.org/10.1177/0149206314547521

[13] DeConinck, J.B. (2011) The Effects of Ethical Climate on Organizational Identification, Supervisory Trust, and Turnover among Salespeople. Journal of Business Research, 64, 617-624. https://doi.org/10.1016/j.jbusres.2010.06.014

[14] Brown, M.E. and Mitchell, M.S. (2010) Ethical and Unethical Leadership: Exploring 
New Avenues for Future Research. Business Ethics Quarterly, 20, 583-616. https://doi.org/10.5840/beq201020439

[15] Connell, J., Ferres, N. and Travaglione, T. (2003) Engendering Trust in Manager-Subordinate Relationships: Predictors and Outcomes. Personnel Review, 32, 569-587. https://doi.org/10.1108/00483480310488342

[16] Young, L. and Daniel, K. (2003) Affectual Trust in the Workplace. International Journal of Human Resource Management, 14, 139-155. https://doi.org/10.1080/09585190210158565

[17] Blois, K. (1998) A Trust Interpretation of Business to Business Relationships: A Case-Based Discussion. Management Decision, 36, 302-308. https://doi.org/10.1108/00251749810220504

[18] Hosmer, L.T. (1995) Trust: The Connecting Link between Organizational Theory and Philosophical Ethics. Academy of Management Review, 20, 379-403. https://doi.org/10.5465/amr.1995.9507312923

[19] DeConinck, J.B. (2010) The Effect of Organizational Justice, Perceived Organizational Support, and Perceived Supervisor Support on Marketing Employees' Level of Trust. Journal of Business Research, 63, 1349-1355. https://doi.org/10.1016/j.jbusres.2010.01.003

[20] Ellis, K. and Shockley-Zalabak, P. (2001) Trust in Top Management and Immediate Supervisor: The Relationship to Satisfaction, Perceived Organizational Effectiveness, and Information Receiving. Communication Quarterly, 49, 382-398. https://doi.org/10.1080/01463370109385637

[21] Hubbard, B. (2017) Saudi Arabia Says 200 Detained in Anti-Corruption Crackdown. The New York Times, A6.

[22] Trong Tuan, L. (2012) The Linkages among Leadership, Trust, and Business Ethics. Social Responsibility Journal, 8, 133-148. https://doi.org/10.1108/17471111211196629

[23] Lu, C.S. and Lin, C.C. (2014) The Effects of Ethical Leadership and Ethical Climate on Employee Ethical Behavior in the International Port Context. Journal of Business Ethics, 124, 209-223. https://doi.org/10.1007/s10551-013-1868-y

[24] Victor, B. and Cullen, J.B. (1987) A Theory and Measure of Ethical Climate in Organizations. In: Frederick, W.C. and Preston, L., Eds., Research in Corporate Social Performance and Policy, JAL, London, 51-71.

[25] Victor, B. and Cullen, J.B. (1988) The Organizational Bases of Ethical Work Climates. Administrative Science Quarterly, 33, 101-125. https://doi.org/10.2307/2392857

[26] Kohlberg, L. (1984) Essays on Moral Development: Vol. 2. The Psychology of Moral Development: Moral Stages, Their Nature and Validity.

[27] Merton, R.K. (1957) The Role-Set: Problems in Sociological Theory. The British Journal of Sociology, 8, 106-120. https://doi.org/10.2307/587363

[28] Gouldner, A.W. (1957) Cosmopolitans and Locals: Toward an Analysis of Latent Social Roles. I. Administrative Science Quarterly, 2, 281-306. https://doi.org/10.2307/2391000

[29] Schneider, B. and Reichers, A.E. (1983) On the Etiology of Climates. Personnel Psychology, 36, 19-39. https://doi.org/10.1111/j.1744-6570.1983.tb00500.x

[30] Agrawal, R.K. (2017) Do Ethical Climates Impact Trust in Management? A Study in Indian Context. International Journal of Organizational Analysis, 25, 804-824. https://doi.org/10.1108/IJOA-08-2016-1053 
[31] Ötken, A.B. and Cenkci, T. (2012) The Impact of Paternalistic Leadership on Ethical Climate: The Moderating Role of Trust in Leader. Journal of Business Ethics, 108, 525-536. https://doi.org/10.1007/s10551-011-1108-2

[32] Victor, B. and Cullen, J.B. (1990) A Theory and Measure of Ethical Climate in Organizations. In: Frederick, W.C. and Preston, L.E., Eds., Business Ethics. Research Issues and Empirical Studies, JAI Press Inc., Greenwich, 77-97.

[33] Deshpande, S.P., George, E. and Joseph, J. (2000) Ethical Climates and Managerial Success in Russian Organizations. Journal of Business Ethics, 23, 211-217. https://doi.org/10.1023/A:1005943017693

[34] Mayer, R.C., Davis, J.H. and Schoorman, F.D. (1995) An Integrative Model of Organizational Trust. Academy of Management Review, 20, 709-734. https://doi.org/10.5465/amr.1995.9508080335

[35] Akker, L.V., Heres, L., Lasthuizen, K. and Six, F.E. (2009) Ethical Leadership and Trust: It's All about Meeting Expectations. International Journal of Leadership Studies, 5, 102-122.

[36] Huff, L. and Kelley, L. (2003) Levels of Organizational Trust in Individualist versus Collectivist Societies: A Seven-Nation Study. Organization Science, 14, 81-90. https://doi.org/10.1287/orsc.14.1.81.12807

[37] McEvily, B., Perrone, V. and Zaheer, A. (2003) Trust as an Organizing Principle. Organization Science, 14, 91-103. https://doi.org/10.1287/orsc.14.1.91.12814

[38] Yakovleva, M., Reilly, R.R. and Werko, R. (2010) Why Do We Trust? Moving beyond Individual to Dyadic Perceptions. Journal of Applied Psychology, 95, 79-91. https://doi.org/10.1037/a0017102

[39] DeConinck, J.B., DeConinck, M.B. and Moss, H.K. (2016) The Relationship among Ethical Leadership, Ethical Climate, Supervisory Trust, and Moral Judgment. Academy of Marketing Studies Journal, 20, 89.

[40] Nyhan, R.C. and Marlowe Jr., H.A. (1997) Development and Psychometric Properties of the Organizational Trust Inventory. Evaluation Review, 21, 614-635. https://doi.org/10.1177/0193841X9702100505

[41] Ruppel, C.P. and Harrington, S.J. (2000) The Relationship of Communication, Ethical Work Climate, and Trust to Commitment and Innovation. Journal of Business Ethics, 25, 313-328. https://doi.org/10.1023/A:1006290432594

[42] Paine, L.S. (1994) Managing for Organizational Integrity. Harvard Business Review, 72, 106-117.

[43] Atwater, L.E. (1988) The Relative Importance of Situational and Individual Variables in Predicting Leader Behavior: The Surprising Impact of Subordinate Trust. Group \& Organization Studies, 13, 290-310. https://doi.org/10.1177/105960118801300304

[44] Cummings, L.L. and Bromiley, P. (1996) The Organizational Trust Inventory (OTI). Trust in Organizations. Frontiers of Theory and Research, 302, 39-52.

[45] Lämsä, A.M. and Pučètaitè, R. (2006) Development of Organizational Trust among Employees from a Contextual Perspective. Business Ethics: A European Review, 15, 130-141. https://doi.org/10.1111/j.1467-8608.2006.00437.x

[46] Guinot, J., Chiva, R. and Mallén, F. (2013) Organizational Trust and Performance: Is Organizational Learning Capability a Missing Link? Journal of Management \& Organization, 19, 559-582. https://doi.org/10.1017/jmo.2014.3

[47] Shockley-Zalabak, P., Ellis, K. and Winograd, G. (2000) Organizational Trust: What It Means, Why It Matters. Organization Development Journal, 18, 35. 
[48] Mulki, J.P., Jaramillo, F. and Locander, W.B. (2006) Effects of Ethical Climate and Supervisory Trust on Salesperson's Job Attitudes and Intentions to Quit. Journal of Personal Selling \& Sales Management, 26, 19-26. https://doi.org/10.2753/PSS0885-3134260102

[49] Werner, O. and Campbell, D.T. (1970) Translating, Working through Interpreters, and the Problem of Decentering. In: Naroll, R. and Cohen, R., Eds., A Handbook of Method in Cultural Anthropology, American Museum of Natural History, New York, 398-420.

[50] McCauley, D.P. and Kuhnert, K.W. (1992) A Theoretical Review and Empirical Investigation of Employee Trust in Management. Public Administration Quarterly, 16, 265-284.

[51] Deshpande, S.P. (1996) Ethical Climate and the Link between Success and Ethical Behavior: An Empirical Investigation of a Non-Profit Organization. Journal of Business Ethics, 15, 315-320. https://doi.org/10.1007/BF00382957

[52] Cullen, J.B., Victor, B. and Bronson, J.W. (1993) The Ethical Climate Questionnaire: An Assessment of Its Development and Validity. Psychological Reports, 73, 667-674. https://doi.org/10.2466/pr0.1993.73.2.667

[53] Schoorman, F.D. and Ballinger, G.A. (2006) Leadership, Trust and Client Service in Veterinary Hospitals. Unpublished Working Paper, Purdue University.

[54] Cohen, J. and Cohen, P. (1983) Applied Multiple Regression/Correlation Analysis for the Behavioral Sciences. 2nd Edition, Erlbaum, Hillsdale.

[55] Stachowicz-Stanusch, A. and Simha, A. (2013) An Empirical Investigation of the Effects of Ethical Climates on Organizational Corruption. Journal of Business Economics and Management, 14, S433-S446.

https://doi.org/10.3846/16111699.2012.744345 